\title{
Chapter 11 \\ The Soil Habitat and Considerations for Synthetic Biology
}

\author{
Robyn A. Barbato
}

Microorganisms serve as agents for synthetic biology. It certain instances, the technology is reliant on survival of the genetically-altered microorganism in the natural environment. This chapter offers insight into the soil system to improve the performance of genetically-altered microorganisms in the natural environment. This chapter covers the soil system, the fitness of genetically-altered organisms, and considerations for their survival and proliferation in nature. This chapter does not discuss the ecological consequences of survival in the natural environment or the regulatory considerations to distribute a genetically-altered organism in the environment. In addition to regulatory approval, both considerations should be critically reviewed before a genetically-altered organism is distributed in the environment.

\subsection{The Soil System}

\subsubsection{Soil Properties}

The soil environment is complex and heterogeneous. Soil is rock that has been broken down and weathered and is combined with organic matter which supports growth of organisms. The soil profile is composed of layers, termed horizons, which are distinct with depth from the soil surface. The $\mathrm{O}$ horizon generally comprises leaf litter. Because of the presence of plant roots and soil microorganisms, the top layer of the soil is the A horizon, which typically harbors a high amount of organic matter. Beneath that horizon is the B horizon, which can harbor materials that have leached

\section{R. A. Barbato $(\triangle)$}

US Army Corps of Engineers Engineer Research Development Center Cold Regions

Research and Engineering Laboratory, Hanover, NH, USA

e-mail: Robyn.A.Barbato@erdc.dren.mil 
from the A horizon above it. The $\mathrm{C}$ horizon is located below the $\mathrm{B}$ horizon. The $\mathrm{C}$ horizon contains rock fragments that have partially weathered.

Soils are also laterally heterogeneous across the landscape. Soil forming factors influence the soil type present at a given location. In an attempt to characterize soils across the landscape, which includes their depth profile, the United States Department of Agriculture developed twelve orders of soil taxonomy, which include alfisols, andisols, aridisols, entisols, gelisols, histosols, inceptisols, mollisols, oxisols, spodosols, ultisols, and vertisols.

The texture of the soil is determined by the proportion of three different types of soil particles, sand, silt, and clay, which vary by their diameter. Sand particles have a diameter ranging from $0.05 \mathrm{~mm}$ to $2.0 \mathrm{~mm}$. Silt particles have a diameter of $0.002 \mathrm{~mm}$ to $0.05 \mathrm{~mm}$. Clay particles have a diameter of less than $0.002 \mathrm{~mm}$. The surface area of these mineral particles is lowest for sand and orders of magnitude higher for clay mineral particles. Clay minerals in particular are influence biological and chemical reactions occurring in the soil, mainly due to their small size and surface charge. The negative charge of clay minerals is an important factor in the soil cation exchange capacity, or the ability of the soil to exchange cations.

The combination of sand, silt, and clay particles determine the soil texture. There are 12 major soil textural classes that are identified in the soil textural triangle. While the texture of the soil can be informative for the combination of mineral particle types, the orientation of these particles in three-dimensional space is more meaningful for the resident microorganisms. The microorganisms live in the soil pores between the soil aggregates. Soil texture is an important factor in the location and type of soil pores present. Soil pores are spaces between the soil aggregates that may be filled with water, air, organic matter, microorganisms, and nutrients (Fig. 11.1). Commonly pores include macropores (greater than $75 \mu \mathrm{m}$ ), micropores $(5-30 \mu \mathrm{m})$, and nanopores $(<0.1 \mu \mathrm{m})$.

Important soil abiotic attributes include soil $\mathrm{pH}$, soil temperature, soil water content, and soil cation exchange capacity. Soil $\mathrm{pH}$ is very important for how chemicals behave in soil and which organisms grow in or on soil. Often, forest soils are acidic,

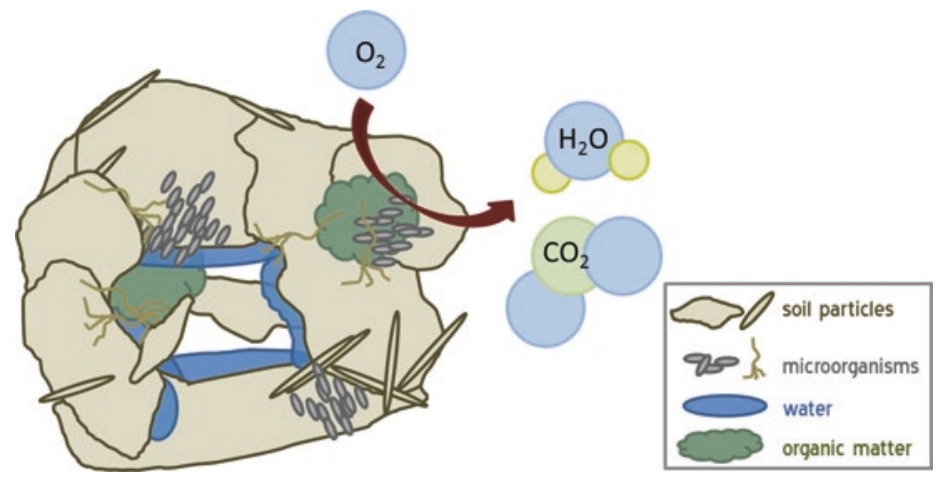

Fig. 11.1 Conceptual model of a soil pore emphasizing soil microorganisms' role in heterotrophic respiration 
while soils located in arid regions are alkaline. Soil temperature influences the activity and rates of processes of organisms in soil. It is highly dependent on the amount of soil water due to the specific heat of water. Soil water potential energy of water held in the soil in relation to the energy of free water. Soil water potential includes matric potential (influence of capillary forces on the system), osmotic potential (influence of solutes on the system), and gravitational potential (influence of gravity to pull the water toward the earth's core). Soil water potential is affected by soil texture. A water release curve is often developed for a type of soil to relate the gravimetric or volumetric water to the matric potential. Soil exchange capacity is the ability of the soil particles themselves to hold either cations or ions. The clay particles influence the soil cation exchange capacity, which in turn influence the types of chemicals which are available to nearby microorganisms.

\subsubsection{Life in Soil}

Soil is teeming with life and supports the growth of plants and animals. Within soil, there are microorganisms at a range of trophic levels which include as viruses, bacteria, archaea, fungi, and protists. At a given moment, approximately $10 \%$ of soil microorganisms are active. The remainder are in a resting metabolic state. There are approximately one billion bacteria in one gram of soil, which includes 1000 different species. Microorganisms reside in the soil pore space. Important soil properties influence the number and types of microorganisms found in the soil.

Microbes live together in soil and do not exist alone. Therefore, ecological interactions between soil microorganisms determine their survival and proliferation. Important ecological interactions in soil include commensalism, mutualism, symbiosis, competition, amensalism, parasitism, predation, and neutralism. The positive ecological interactions are when at least one group benefits from an interaction. Positive ecological interactions include commensalism, mutualism, and symbiosis. In commensalism, one microorganism functions and another microorganism gains from that function. Mutualism is a positive ecological interaction where both microorganisms benefit. Symbiosis is where two microorganisms benefit to the extent that they cannot survive without one another. Negative ecological interactions include competition, amensalism, parasitism, and predation. Microorganisms compete over substrates for growth and/or metabolism. They might be superior in their genetic capacity to use a substrate and/or physically faster to access it through motility. Amensalism is a negative ecological interaction where one microorganism suppresses the growth or function of another microorganism through the production of compounds. A classic example of amensalism is the production of antibiotics by the fungus Penicillium to kill nearby bacteria susceptible to it. Both parasitism and predation include feeding on living microorganisms thereby suppressing the host's or prey's ability to function. Neutralism is an ecological interaction where neither microorganism benefits from the interaction. These interactions are unlikely in soil and difficult to define in a diverse, heterogeneous environments. 
Life in soil is driven by the active microorganisms present, their access to substrates, and their genetic capacity to make enzymes to break down the substrates. Soils are generally oligotrophic, which means that they are low-nutrient systems. Depending on their geographic location, they may experience vastly different conditions throughout the day or the year. For instance, precipitation could dramatically change the water potential of a soil and in turn either create anoxic conditions and/ or cause a release of substrates from one soil pore to another. Diurnal temperature cycles could span beyond the temperature optimum for resident microorganisms. Therefore, groups of microorganisms develop survival strategies to thrive under a particular set of conditions. The development of new tools to survey microorganisms will enable understanding of the spatial and temporal effects on microbial community composition and function in soils. The Earth Microbiome Project encouraged the collection of microorganisms in the field and offered a repository for the number and types of microorganisms present at a given location at the time of collection (Gilbert et al. 2010, 2014). Concurrently, soil samples are collected to culture microorganisms in the laboratory. The vast number, types, metabolic preference, and growth requirements of the microorganisms make culturing challenging. Nonetheless, it is an important step to understanding the range of metabolism and growth of the organisms.

\subsection{Fitness of Genetically-Altered Organisms}

\subsubsection{Fitness of Domesticated Microorganisms}

There have been recent advancements in the field of synthetic biology that resulted in new genetically-altered organisms. Often, microorganisms such as Escherichia coli (a bacterium) and Saccharomyces cerevisiae (a yeast) are popular targets for genetic manipulation. They are common chassis, which physically house genetic components and provide resources (i.e. transcription and translation machinery) for the organism to function (Danchin 2012; Brophy et al. 2018; Westmann et al. 2018; Trump et al. 2018). This is largely driven by the depth of knowledge and research on these organisms. They have been domesticated in the laboratory through multiple enrichments and manipulations. There is a wealth of information how their genetic material encodes for specific metabolism. Control of the growth and metabolism of these microorganisms through synthetic biology tools is extraordinary. These organisms have met the criteria identified to be an effective chassis which include that the organism grows easily, has a robust cellular envelope, transcription and translation can be controlled, their growth and metabolism is well understood, and they have low mutation rates (Foley and Shuler 2010). 


\subsection{Considerations for Survival in Soil}

\subsubsection{Soil Conditions Influence Growth}

Life in soil is stressful. The soil properties described earlier in this chapter influence the composition and function of soil microbes. Soil microorganisms are reliant on either narrow or broad conditions to proliferate and metabolize substrates. Soil properties such as water potential, organic matter content, particle size distribution, and temperature influence biological activity and collectively define the state of soils. Soil temperature influences soil activity, with warmer soils typically experiencing higher rates of processes (Lloyd and Taylor 1994; Hanson et al. 2000; Fierer et al. 2006). Soil moisture also influences soil activity (Fierer et al. 2003; Schimel et al. 2007; Xiang et al. 2008; Borken and Matzner 2009; Fóti et al. 2014). The optimal matric potential for microbial activity in is $-33 \mathrm{kPa}$. When the soil is too dry, soil activity is reduced or stops completely (Manzoni et al. 2012). At this point, substrate diffusion is limited, and therefore there are no substrates bioavailable for nearby soil microbes. When a soil is too wet, the diffusion of oxygen to aerobic microorganisms is limited. Concurrently, anaerobic microorganisms (those which use compounds other than oxygen as electron acceptors) become active.

\subsubsection{Microbial Adaptations}

Microorganisms have adapted and continue to adapt to the soil conditions. Therefore, ecological niches defined by ecological interactions and physiochemical factors are occupied. Disturbance events such as physical soil manipulation or the addition of a chemical often change the niches available to groups of microorganisms. Absence of a disturbance, the ability of an introduced microorganism to gain a foothold in the soil system is less likely. Often, the introduced microorganisms are not adapted to the conditions and are quickly outcompeted by nearby microorganisms. Unless they fulfill a key ecological role, they are likely diluted out of the soil system until they become extinct.

\subsubsection{Fitness of Microorganisms in Soil}

As synthetic biology advances, important considerations need to be considered to ensure optimal performance in the natural environment. Domesticated organisms likely lack fitness under the stressful conditions of soil, as soil conditions often do not meet the metabolic needs of these organisms and indigenous soil microorganisms are more adept to acquire substrates to survive. Though genetic expression and regulation of synthetic circuits are highly host-specific, the best candidates for 
fieldable chassis are likely environmental microbes that have adapted to survive under dynamic conditions (Tanner et al. 2017). In doing so, genetic engineering augments the process that natural selection has already optimized.

The high diversity in soil offers the opportunity to develop new chassis capable of surviving in the natural environment. There have been recent advances is the phylogenetic classification of soil microorganisms. Using sequencing technologies, the taxonomy of microorganisms in a given soil can be identified. Through culturing and phenotypic characterization, discoveries of novel microorganisms are possible. Because these microorganisms are originating from the environment they will be returned, they may be more adept to surviving the challenging conditions common to most soil environments. This implies that they retain the genetic advantages for survival under dynamic physical and chemical conditions.

\subsection{Conclusions}

The soil system is complex and heterogeneous in space and in time. Soils are highly diverse and present a source and a sink for new products for synthetic biology. Important considerations for survival in soil have been outlined in this chapter. Furthermore, these concepts can be extended to situations where genetically-altered microorganisms are added to the soil matrix to perform a specific function. Because soils are so heterogeneous, a singular approach is unlikely to be successfully applied to multiple soil systems. Understanding soils and the multitude of ecological interactions occurring within them is key to promote the survival of introduced organisms to that particular environment.

\section{References}

Borken W, Matzner E (2009) Reappraisal of drying and wetting effects on C and N mineralization and fluxes in soils. Glob Chang Biol 15(4):808-824

Brophy JAN, Triassi AJ, Adams BL, Renberg RL, Stratis-Cullum DN, Grossman AD, Voight CA (2018) Engineered integrative and conjugative elements for efficient and inducible DNA transfer to undomesticated bacteria. Nat Microbiol 3:1043-1053

Danchin A (2012) Scaling up synthetic biology: do not forget the chassis. FEBS Lett 23586:2129-2137

Fierer N, Schimel JP, Holden PA (2003) Influence of drying-rewetting frequency on soil bacterial community structure. Microb Ecol 45(1):63-71

Fierer N, Colman BP, Schimel JP, Jackson RB (2006) Predicting the temperature dependence of microbial respiration in soil: a continental-scale analysis. Glob Biogeochem Cycles 20(3):GB3026

Foley PL, Shuler ML (2010) Considerations for the design and construction of a synthetic platform cell for biotechnological applications. Biotechnol Bioeng 105(1):26-36 
Fóti S, Balogh J, Nagy Z, Herbst M, Pintér K, Péli E, Koncz P, Bartha S (2014) Soil moisture induced changes on fine-scale spatial pattern of soil respiration in a semi-arid sandy grassland. Geoderma 213:245-254

Gilbert JA, Meyer F, Jansson J, Gordon J, Pace N, Tiedje J, Ley R, Fierer N, Field D, Kyrpides N, Glöckner FO (2010) The earth microbiome project: meeting report of the "1 st EMP meeting on sample selection and acquisition" at Argonne National Laboratory October 6 th 2010. Stand Genomic Sci 3:249-253

Gilbert JA, Jansson JK, Knight R (2014) The Earth Microbiome project: successes and aspirations. BMC Biol 12:1-4

Hanson PJ, Edwards NT, Garten CT, Andrews JA (2000) Separating root and soil microbial contributions to soil respiration: a review of methods and observations. Biogeochemistry 25:1537-1546

Lloyd J, Taylor JA (1994) On the temperature dependence of soil respiration. Funct Ecol 8(3):315

Manzoni S, Schimel JP, Porporato A (2012) Responses of soil microbial communities to water stress: results from a meta-analysis. Ecology 93(4):930-938

Schimel J, Balser TC, Wallenstein M (2007) Microbial stress-response physiology and its implications for ecosystem function. Ecology 88:1386-1394

Tanner K, Vilanova C, Porcar M (2017) Bioprospecting challenges in unusual environments. Microb Biotechnol 10:671

Westmann CA, Guazzaroni ME, Silva-Rocha R (2018) Engineering complexity in bacterial regulatory circuits for biotechnological applications. Msystems 3:2

Xiang S-R, Doyle A, Holden PA, Schimel JP (2008) Drying and rewetting effects on C and N mineralization and microbial activity in surface and subsurface California grassland soils. Soil Biol Biochem 40(9):2281-2289

Open Access This chapter is licensed under the terms of the Creative Commons Attribution 4.0 International License (http://creativecommons.org/licenses/by/4.0/), which permits use, sharing, adaptation, distribution and reproduction in any medium or format, as long as you give appropriate credit to the original author(s) and the source, provide a link to the Creative Commons license and indicate if changes were made.

The images or other third party material in this chapter are included in the chapter's Creative Commons license, unless indicated otherwise in a credit line to the material. If material is not included in the chapter's Creative Commons license and your intended use is not permitted by statutory regulation or exceeds the permitted use, you will need to obtain permission directly from the copyright holder. 